\title{
Barriers to tacit knowledge retention: An understanding of the perceptions of the knowledge management of people inside and outside the organisation
}

\begin{tabular}{|c|c|}
\hline \multicolumn{2}{|l|}{$\begin{array}{l}\text { Authors: } \\
\text { Jacky Bessick }{ }^{1} \\
\text { Visvanathan } \mathrm{N}\end{array}$} \\
\hline \multicolumn{2}{|c|}{$\begin{array}{l}\text { Affiliations: } \\
1 \text { Information Systems } \\
\text { Department, University } \\
\text { of the Western Cape, } \\
\text { South Africa }\end{array}$} \\
\hline \multicolumn{2}{|c|}{$\begin{array}{l}{ }^{2} \text { Graduate School of Business } \\
\text { Leadership, University of } \\
\text { South Africa, South Africa }\end{array}$} \\
\hline \multicolumn{2}{|c|}{$\begin{array}{l}\text { Correspondence to: } \\
\text { Visvanathan Naicker }\end{array}$} \\
\hline \multicolumn{2}{|c|}{$\begin{array}{l}\text { Email: } \\
\text { vnaicker@uwc.ac.za }\end{array}$} \\
\hline \multicolumn{2}{|c|}{$\begin{array}{l}\text { Postal address: } \\
\text { Private Bag X17, Modderdam } \\
\text { Road, Bellville, Cape Town } \\
\text { 7535, South Africa }\end{array}$} \\
\hline \multicolumn{2}{|c|}{$\begin{array}{l}\text { Dates: } \\
\text { Received: } 08 \text { Feb. } 2013 \\
\text { Accepted: } 04 \text { June } 2013 \\
\text { Published: } 25 \text { July } 2013\end{array}$} \\
\hline \multicolumn{2}{|c|}{$\begin{array}{l}\text { How to cite this article: } \\
\text { Bessick, J. \& Naicker, V., 2013, } \\
\text { 'Barriers to tacit knowledge } \\
\text { retention: An understanding } \\
\text { of the perceptions of the } \\
\text { knowledge management of } \\
\text { people inside and outside } \\
\text { the organisation', SA Journal } \\
\text { of Information Management } \\
\text { 15(2), Art. \#556, 8 pages. } \\
\text { http://dx.doi.org/10.4102/ } \\
\text { sajim.v15i2.556 }\end{array}$} \\
\hline \multicolumn{2}{|c|}{$\begin{array}{l}\text { Copyright: } \\
\text { (C) 2013. The Authors. } \\
\text { Licensee: AOSIS } \\
\text { OpenJournals. This work } \\
\text { is licensed under the } \\
\text { Creative Commons } \\
\text { Attribution License. }\end{array}$} \\
\hline \multicolumn{2}{|l|}{ Read online: } \\
\hline 口irita & $\begin{array}{l}\text { Scan this QR } \\
\text { code with your } \\
\text { smart phone or } \\
\text { mobile device } \\
\text { to read online. }\end{array}$ \\
\hline
\end{tabular}

Background: Knowledge loss causes challenges for organisations that wish to remain competitive. These organisations must identify the risks that could lead to knowledge loss and become aware of issues that affect knowledge retention.

Objectives: The objective of this research was to identify tacit knowledge retention barriers that could cause knowledge loss in an organisation. The paper presents a framework for the assessment of the impact of these barriers and discusses the research findings in order to critique that framework.

Method: A quantitative strategy was used to interpret the findings. The target population is information technology (IT) professionals in a government organisation. Interviews were conducted in order to produce a more context-sensitive interpretation of the findings. A quantitative research approach was used to ensure the findings would precisely reflect the target population.

Results: The majority of respondents confirmed that career development requires professional development, training prospects and improves the employability of employees. The agreed result was that respondents seek autonomy, that is, the ability to make decisions. Job stress and burnout are experienced because of problems with in filling posts, and the competition between the private and public sectors for experienced IT employees.

Conclusion: Certain determinants were found that affect barriers in knowledge management: organisational commitment, job satisfaction, job characteristics and talent management. These need to be measured to prevent barriers from occurring. Implications are drawn from the study; these provide a focus for further research to bridge some gaps in information technology that currently limit the widespread use of knowledge management.

\section{Introduction}

As organisations evolve and render services, their employees gain experience and knowledge about their domain, the competitive environment and the client requirements. As this body of knowledge grows, it becomes more valuable, and develops the characteristics of an asset, which needs to be nurtured and utilised. Companies that value this asset tend to be more successful than those that have not yet recognised this fact. In a shrinking economy, this could mean the difference between the survival and failure of a business. The knowledge is typically gained by individuals who are not normally compelled to share or document it.

In environments where knowledge sharing is not the norm, staff can become the sole owners of domain knowledge, meaning that this knowledge is typically lost when the employee leaves an organisation. There will always be the risk that valuable knowledge is lost to an organisation that does not protect its information through a documented business process. Hence, this research seeks to investigate what the barriers are to tacit knowledge retention.

Knowledge management (KM) promotes classification, administration and sharing of an organisation's information assets. An information asset is organised information that is valuable and easily accessible to those who need it. Knowledge exists within the individual employees and is a key component for organisations that wish to be and remain competitive in the marketplace. It is therefore imperative for organisations to recognise it as a valuable resource (Bollinger \& Smith 2001; Bender \& Fish 2000).

According to Wiig (1997), management must focus on four areas in order to retain knowledge: initiating governance functions, focusing on staff functions, accepting the responsibility for operation functions to create, renew, organise and transfer knowledge assets, and leveraging 
knowledge assets, thereby ensuring knowledge is distributed and applied effectively through collaboration. Arif et al. (2009) present a retention model, which consists of a four-step process: socialisation, codification, knowledge construction and knowledge retrieval. Lee-Kelly, Blackman \& Hurst (2007) state that the challenge in retaining knowledgeable workers is due to the relationships between a learning organisation, job satisfaction and the turnover of knowledge workers. The present exploratory fieldwork is intended to contribute to an understanding of the perceptions of KM by people both inside and outside the organisation.

\section{Research problem}

Most of existing research theory has revealed organisational commitment, which reflects the strength of the linkage between the employee and the organisation. Job satisfaction, which describes how comfortable the employees are in their jobs, and job characteristics, which describe the aspects specific to a job, constitute the main determinants that influence the retention of knowledge. Implementing strategies can ensure that the employees achieve the benefit they deserve. Hence, knowledge is retained, and barriers are overcome in the organisation. Coombs (2009), Lock (2003) and Van Dijk (2008) are of the view that an organisation should succeed if knowledge is retained by increasing the level of determinants, namely organisational commitment, job satisfaction, job characteristics and talent management.

\section{Research questions}

Valuable organisational knowledge is lost when experienced employees leave an organisation. Hence, the main research question is stated as: What are the barriers to tacit knowledge retention in a South African government organisation?

In addition, the following research sub-questions were also investigated:

- What is knowledge retention?

- What are the typical barriers to tacit knowledge retention?

- How do barriers impact knowledge retention in government organisations?

\section{Literature review}

This literature aims to understand the barriers to knowledge retention of information technology (IT) professionals in the public sector in South Africa. Rong and Grover (2009) articulate that knowledge is an important success factor for organisations; it influences performance and learning to uphold organisational competitiveness. Nonaka and Takeuchi (1995) separated knowledge into explicit and tacit knowledge bases. They claim that explicit knowledge can be transferred through KM mechanisms, such as document storage or electronic media, and that it is outside the human mind. Tacit knowledge, however, can only be transferred by the individual knowledge carrier; it cannot be captured, and is difficult to articulate explicitly. However, explicit knowledge can be expressed as a language, and may be conveyed amongst individuals (Bhardwaj \& Monin 2006).
According to Kikoski, as cited by Alwis and Hartmann (2008), tacit knowledge is less known; it is an unusual form of knowledge, of which we are not really aware. Furthermore, it is not exchanged through language, but is acquired by sharing experiences and by observation (Alwis \& Hartmann 2008). Therefore, tacit knowledge is considered more valuable, because it offers a context for people's thoughts, places and experiences. It normally requires considerable personal interaction and trust to share effectively (McAdam, Mason \& McCrory 2007). Hence, a knowledge worker (KW) may be described as a person who wants to be valued for knowledge they own and who works with intangible resources. The desires and views of such people incorporate those of an expert or a thinker. Such people want to transform their knowledge, contribute to solving problems and effortlessly influence the organisation's decision making, strategic direction and priorities. Drucker (1959) states that there are three important stages organisations must go through in order for knowledge processes to be valued, captured and measured:

1. utilise creative knowledge

2. recognise that KWs add value to the organisation

3. introduce formalised education programmes to allow the knowledge workers to apply their knowledge, both theoretically and analytically. (n.p.)

Davenport and Prusak (as cited by Ramirez \& Nembhard 2004) define a KW as a person who creates knowledge or uses knowledge in an influential way in the workplace: 'KWs [are] people with a high degree of education or expertise whose work primarily involves the creation, distribution or application of knowledge'.

Prusak (2001) affirms that KM is about people, the processes they apply to gather, share, transform, teach, learn and make use of information. According to Depres and Chauvel (1999), $\mathrm{KM}$ is an approach to improve efficiency, productivity, transparency and outward sharing of information that is used internally in decision making, thereby improving working relations and trust for workers in an organisation.

\section{Knowledge sharing}

Wang (2004) explains that knowledge sharing (KS) activities among the employees enable cooperation and are vitally important in shaping the organisation's investment. Hsu (cited by Jiacheng, Lu \& Francesco 2010) describes KS as a form of individual behaviour that makes it possible to disseminate or transfer knowledge that has been created throughout the organisation. Reychav and Weisberg (2010) suggest that organisations have to acknowledge that knowledge represents a valuable intangible asset for creating and sustaining a competitive advantage. Knowledge sharing can occur when there is a relationship amongst employees - through trust and an open organisational structure - to facilitate transparent knowledge flows, and to provide an organisational culture of continuous learning (Riege 2005). Organisations face the challenge of losing knowledge from baby boomers (people born between 1945 and 1960). This could affect organisational performance negatively and would 
require the introduction of effective initiatives to transfer knowledge to the new generation of employees. This would mitigate the risk of any loss of productivity and profitability (Claes \& Heymans 2008).

According to Riege (2005), the following KS barriers exist in some organisations:

1. Individual barriers, such as age and gender differences.

2. Differences in education levels.

3. Lack of trust and the failure to take ownership of intellectual property.

4. Organisational barriers, such as the lack of leadership and managerial direction.

5. The integration of KM strategy, and the sharing of initiatives in the company's goals.

6. Knowledge retention of highly skilled and experienced staff is not always a high priority; the lack of transparent rewards and recognition are both counterproductive.

7. Technological barriers, such as a lack of integration and the compatibility of IT systems and processes.

8. Reluctance to use IT systems.

9. Lack of technical support and lack of communication.

10. The lack of demonstration of all advantages of any new systems in preference to the existing ones. (n.p.)

\section{Critical success factors for knowledge management}

According to Girard and McIntyre (2010), KM initiative depends on many factors for success. These can be organised into five primary categories: leadership, culture, roles and responsibilities, information technology infrastructure and measurement.

Furthermore, managers should create a vision for KM, assist in directing the change effort, and develop strategies for achieving the vision. The chosen structure employed in a KM leadership group should model and teach employees and stakeholders the importance of KS and using a common vocabulary. Context-sensitive and user-friendly technology that guides the user to the information with ease could improve adoption rates, and training using bestpractice examples would help when searching and sharing information quickly.

Measurement before, during and after the phased implementation of KM would make it possible to link KM efforts with some return on the initial investment. Figure 1 depicts the basic model presented by Joseph et al. (2007). This will be utilised in this research, as it defines the determinants: job satisfaction and organisational commitment.

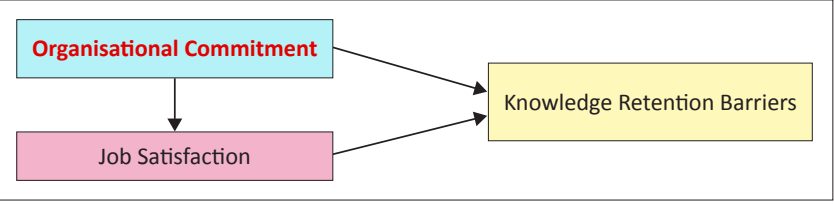

Source: Joseph, D., Ng, K.Y., Koh, C. \& Ang, S., 2007, Turnover of information technology professionals: A narrative review, meta-analytic structural equation modelling and mode development', MIS Quarterly 31(3), 547-577.

FIGURE 1: The old model.
A comprehensive review of the general KM literature revealed that there are a variety of dimensions to KM barriers (Lehner \& Haas 2010). However, not all of these dimensions are equally important, nor are all of these relevant for the government sector. This study focuses on five dimensions that are cited most frequently in the KM literature; and these will now be discussed.

Organisational commitment: As defined by Coombs (2009), is the extent to which an employee experiences a 'sense of oneness' with their organisation and the employee's level of commitment to stay with an organisation. Associated factors, such as loyalty, trust, work-life policies, procedural justice and career development, have a potential influence that may cause a barrier to employees in an organisation. According to Greenhaus and Beutell (as cited by Bashir \& Ramay 2008), work-life policies have an impact on work-life conflict, which they define as an incompatibility between responsibilities in the working environment and those to the family. Basher and Ramay (2008) indicate that a lack of work-life policies has a negative impact on organisational commitment. Wong, Tong and Mula (2009), Döckel, Basson and Coetzee (2006) and McKnight, Phillips and Hardgrave (2009) report that in order to develop employee trust in an organisation, management should steer clear of creating insincere promises that cannot be delivered on or commitments that cannot be achieved. IT professionals appreciate an open communication channel, in which management shares information regarding the business regularly and KS between colleagues can also occur.

Job satisfaction: This is an important organisational variable, and involves factors such as rewards, incentives, work exhaustion, competition and absenteeism. The word 'reward' is repeatedly discussed in the literature as an incentive that an organisation gives to employees in return for their involvement and performance; it can take the form of recognition, which is what employees most want (Allen et al. 2008, and Döckel et al. 2006). Lock (2003) states that a reward is a cash bonus or naming an employee 'employee of the month'. Potgieter and Pretorius (2009) affirm that incentives increase job satisfaction and deliver results that contribute to the organisation's goals.

It is evident from these employees that a lack of incentives worsens problems and produces poor results and the ballooning of costs in delivering systems. Extreme demands on time, such as being on call over weekends and vacations, can certainly lead to work exhaustion. Coombs (2009) and Lock (2003) both confirm that low morale, job stress and burnout experienced by public sector IT professionals are due to the problems that exist in filling posts. In addition, some factors that contribute to job satisfaction are competition between the private and public sector for experienced IT employees, the civil system that focuses on rules and regulations, control systems, the political situation and limited autonomy.

Job characteristics: As defined by Earle (2003), are those aspects that are specific to a job, for example knowledge and skills, mental and physical demands and working conditions that can be recognised, defined, and assessed. The IT 
professionals she surveyed in her study who earned a poor salary endeavoured to seek employment elsewhere. Allen et al. (2008) affirm that in order to retain or attract IT professionals, organisations should establish a positive relationship with employees and provide a pay enhancement programme. Coombs (2009) and Lacity, Iyer and Rudramuniyaiah (2008) believe that employees who seek autonomy demonstrate the ability to make decisions that are challenging and interesting and desire opportunities to apply these to their work activities. Coombs also states that employees want freedom and discretion in the arrangement of their work, and in determining work procedures; this has a positive influence on work performance. They also want responsibility for the outcome of their work and increased work motivation. According to McKnight et al. (2009), supervisor support is a developed relationship, characterised as being a partnership between a supervisor and his subordinates, and involves support, trust, information sharing, respect, career progress and valuing a mutual relationship. Lacity et al. (2008) state that a lack of supervisor support creates an undesirable attitude. This may contribute to poor work performance, lack of trust and poor support from subordinates.

Talent management: As argued by Joubert (cited by Van Dijk 2008), is a human resource process that produces an essential benefit for an organisation. Mentoring development (as described by Allen et al. 2008) is an informal training vehicle to improve the quality of human resource development. Glen (2007) indicates that mentoring development, employee competence and recruiting are factors associated with talent management. Van Dijk (2008) confirms that mentors play a vital role for IT professionals in providing opportunities for learning and career development and promoting the transfer of knowledge to ensure continuity of corporate knowledge. Mentoring development is a tangible approach to demonstrate that employees are valued and have a future in the organisation, and ensures that the organisation retains the best employees. Cunningham (2007) and Earle (2003) state that in order to recruit the best potential person for the job, the characteristics of the organisation must fit; the candidate's values and work attitude should be the focal point during a recruitment process, rather than just their specific skills and experience. Rectifying a wrong value fit choice is typically a very costly exercise.

Moreover, Allen et al. (2008) state that in the public sector there are various factors to consider:

- Lack of a reward system - IT professionals who are discouraged work defensively and not creatively; this can impact negatively on service delivery to the customers.

- Poor salaries influence IT professionals to find jobs elsewhere, which would prevent core knowledge from being retained within an organisation.

- Work exhaustion and burnout are the result of continued impractical work demands on the employee, which leads to a lack of innovative thinking and innovative services.

- The lack of time and the lack of mentor training and understanding prevent the transfer and sharing of knowledge; this results in continued poor skill outcomes, and can affect service delivery negatively. (n.p.)
According to Lockwood and Ansari (1999), knowledge retention includes all activities to protect knowledge in the organisation. Knowledge retention comprises three activities: acquisition, storage and retrieval. Further, Marshall (2005) affirms that knowledge retention is a division of $\mathrm{KM}$, in which organisations use their combined intelligence to achieve their objectives by managing their cultural, social and technological environment.

Finally, the literature review reveals that barriers to knowledge retention do exist in IT organisations. Based on the literature, it is clear that organisations need to provide employees with incentives: financial or non-financial rewards, encouragement from management to share knowledge amongst employees, career development and mentoring programmes to retain knowledge. It is also clear that loyalty and trust contribute to employee behaviour, and need to be nurtured, as these qualities are of strategic importance to an organisation.

Other barriers are work-life policies, work-life conflict, poor salaries, relationships amongst colleagues and supervisory support. It is evident from the literature that the key success factor for a knowledge organisation is to grow, attract and retain talent.

Based on the above theoretical support, the researchers were interested to include two additional determinants: job characteristics and talent management, as these may be driving forces in knowledge retention barriers. The updated model is shown in Figure 2.

\section{Research design and methodology}

A quantitative method approach was used to collect the data. The choice was made to apply the quantitative research approach to ensure that the findings would precisely reflect the population, and in particular that population from which the sample was drawn (Vanderstoep \& Johnston 2009). In this study, the target population was IT professionals in a government organisation. Simple random sampling was employed for this study.

According to Christensen, Johnson and Turner (2009), simple random sampling is the best sampling method to use to ensure an equal probability for all items in the population. Ten completed questionnaires were collected; these were used as a pilot study and were excluded from the main data collection process.

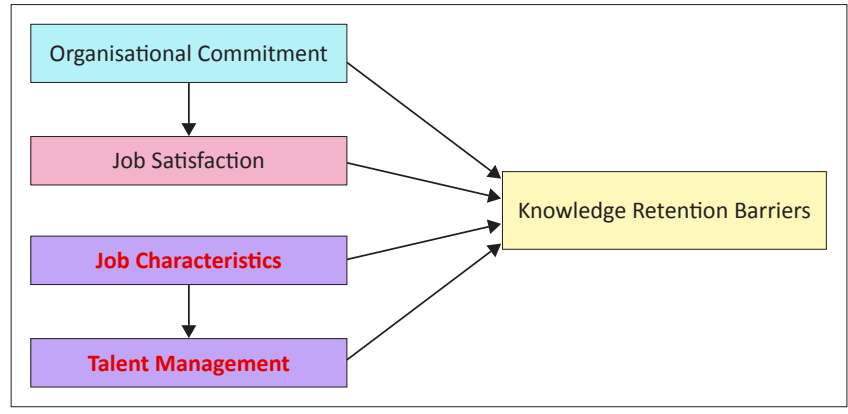

FIGURE 2: New model. 
A total of 230 staff is employed by this branch, of which 60 individuals were asked to participate in the quantitative study. A closed-ended questionnaire was developed with brief answers based on a five-point Likert scale (see Table 3). The content of the questionnaire was developed after reviewing the literature on factors influencing the determinants' organisational commitment, job satisfaction and job characteristics.

The researchers held short interviews with the participants after completion of the questionnaire, to discuss whether, in their opinion, the questions were fair, whether any question offended them, and whether it was easy to complete. The results were used to make adjustments to the structure of two questions that the pilot group identified as making the questionnaire too long.

The questionnaire consisted of 30 questions, which were developed using the insight gained from the literature review. The literature review established a number of factors within each determinant that could be used to retain knowledge in the organisation. These factors were grouped under organisational commitment, job satisfaction, job characteristics and talent management. Statements were developed and presented in a questionnaire to determine whether the factors would introduce any barriers into the organisation.

Table 1 presents a summary of the statements, the supporting factors and the determinants.

\begin{tabular}{lll}
$\begin{array}{l}\text { TABLE 1: Statements and supporting factors. } \\
\text { Statement }\end{array}$ & Factor & \\
\hline 7 & Determinant \\
\hline 8 & Supervisor support & Job Characteristics \\
9 & Poor salary & Job Characteristics \\
10 & Work-life support & Job Characteristics \\
11 & Autonomy & Job Characteristics \\
12 & Training & Job Characteristics \\
13 & Financial reward & Job Satisfaction \\
14 & Non-financial reward & Job Satisfaction \\
15 & Absenteeism (scheduled leave) & Job Satisfaction \\
16 & Absenteeism & Job Satisfaction \\
17 & Burnout and job stress & Job Satisfaction \\
18 & Working environment & Job Satisfaction \\
19 & Loyalty & Organisational Commitment \\
20 & Procedural justice & Organisational Commitment \\
\hline 21 & Trust & Organisational Commitment \\
22 & Information sharing & Organisational Commitment \\
23 & Career development & Organisational Commitment \\
24 & Mentoring development & Talent Management \\
25 & Recruiting & Talent Management \\
\hline & Employee competence & Talent Management \\
\hline
\end{tabular}

TABLE 2: Overall statements to measure determinants.

\begin{tabular}{ll}
\hline Determinant & Statement number \\
\hline Job Characteristics & 26 \\
Job Satisfaction & 27 \\
Organisational Commitment & 28 \\
Retention Commitment & 29 \\
Talent Management & 30 \\
Overall Knowledge Retention & 31 \\
\hline
\end{tabular}

Overall statements that were developed in the questionnaire to measure the determinants are presented in Table 2, and they reaffirm the respondents' views. Furthermore, it was identified which determinants and factors appear to be negative and need management attention.

Statements 26, 27, 28 and 30 were used to measure whether a determinant was negative or positive. The factors that were sorted into each determinant in statements 7-25 were measured to determine whether a barrier or a gap was highlighted as negative (-) or positive (+) in the model. These results determined whether a determinant was a barrier or a gap. Statement 29 was used to measure the respondents' retention commitment. Statement 31 was used to measure the respondents' knowledge retention.

60 participants were targeted; 56 questionnaires were returned. These were checked for accuracy and completeness. Two participants telephonically contacted the researcher after the data had been captured and their questionnaires were therefore not included; two individuals did not complete the questionnaire at all. A return rate of $94 \%$ was reached. The categories of data were compiled for an ordinal dataset. The data analysis was completed using Microsoft Excel. This meant that the data capturing time was reduced to a minimum, which facilitated ease of analysis.

Tables and percentages were used to present and interpret the numerical data. The purpose of analysing the data in table format, categorised and displayed in textual and numerical form, allowed for fast viewing.

\section{Demographic data}

Section A of the questionnaire contained the demographic data items, statements $1-6$. Of the 56 respondents whose questionnaires were analysed, $41 \%$ had worked for the organisation for 11 years or more and $29 \%$ had the designation of being middle management. The majority $(80 \%)$ of the respondents were male, $57 \%$ indicated that their first language was English, 39\% were between the ages of 31 and 40 , and $64 \%$ indicated that they had a diploma or a degree.

\section{Research questionnaire and results}

The research was conducted in Cape Town, at an Information Communication Technology company. The responses from statements 7-31 obtained from the respondents are summarised as percentages in Table 3.

\section{Discussion}

Only statements that displayed significant changes have been discussed, due to space constraints. Statement 7 was obtained from the literature, and confirms that career development requires opportunities for professional development, training prospects and career advancement opportunities and improves the employability of the employees to the organisation. According to McKnight et al. (2009), supervisor support requires a developed relationship, 


\begin{tabular}{|c|c|c|c|c|c|c|}
\hline $\begin{array}{l}\text { Statement } \\
\text { number }\end{array}$ & Response & $\begin{array}{c}\text { Strongly } \\
\text { disagree (\%) }\end{array}$ & Disagree (\%) & Uncertain (\%) & Agree (\%) & $\begin{array}{c}\text { Strongly agree } \\
(\%)\end{array}$ \\
\hline \multicolumn{7}{|c|}{ Job Characteristics } \\
\hline 7 & I receive constant support from my supervisor on my career development. & 13 & 12 & 14 & 45 & 7 \\
\hline 8 & I am paid enough for the work I do. & 13 & 38 & 11 & 34 & 4 \\
\hline 9 & My organisation subscribes to a work-life support programme. & 13 & 14 & 27 & 41 & 5 \\
\hline 10 & I have the freedom to make decisions. & 5 & 29 & 22 & 39 & 5 \\
\hline 11 & My supervisor arranges training pertaining to my job. & 5 & 25 & 4 & 52 & 14 \\
\hline \multicolumn{7}{|c|}{ Job Satisfaction } \\
\hline 12 & I receive a financial reward for my job. & 13 & 32 & 21 & 30 & 4 \\
\hline 13 & I receive a non-financial reward for my job. & 20 & 44 & 16 & 15 & 5 \\
\hline 14 & I am off work for voluntary reasons. & 10 & 19 & 13 & 37 & 21 \\
\hline 15 & I am off work for involuntary reasons. & 23 & 43 & 15 & 17 & 2 \\
\hline 16 & I experience a lot of stress and burnout in my job. & 2 & 25 & 11 & 42 & 20 \\
\hline 17 & I am comfortable in my working environment. & 17 & 20 & 11 & 59 & 5 \\
\hline 18 & I continuously provide my services to the organisation. & 0 & 0 & 2 & 60 & 38 \\
\hline 19 & Our rules and procedures are fairly applied to all employees. & 27 & 20 & 23 & 28 & 2 \\
\hline 20 & Overall, we have very capable and proficient senior management. & 14 & 29 & 32 & 23 & 2 \\
\hline 21 & In my group, information is shared freely. & 7 & 31 & 13 & 44 & 5 \\
\hline 22 & My organisation offers career development. & 13 & 21 & 20 & 46 & 0 \\
\hline \multicolumn{7}{|c|}{ Talent Management } \\
\hline 23 & I have a mentor to support me in my current job. & 15 & 42 & 13 & 28 & 2 \\
\hline 24 & My organisation recruits the best person for the job. & 18 & 39 & 27 & 16 & 0 \\
\hline 25 & We have competent employees in the organisation. & 7 & 23 & 25 & 45 & 0 \\
\hline \multicolumn{7}{|c|}{ Job Characteristics } \\
\hline 26 & I am satisfied with the benefits my organisation offers. & 6 & 25 & 22 & 45 & 2 \\
\hline \multicolumn{7}{|c|}{ Job Satisfaction } \\
\hline 27 & I am satisfied with my job. & 4 & 12 & 9 & 73 & 2 \\
\hline \multicolumn{7}{|c|}{ Organisational Commitment } \\
\hline 28 & I have a strong commitment to continue my services in this organisation. & 4 & 5 & 22 & 55 & 14 \\
\hline \multicolumn{7}{|c|}{ Talent Management } \\
\hline 30 & My organisation subscribes to an individual development plan. & 24 & 40 & 12 & 24 & 0 \\
\hline \multicolumn{7}{|c|}{ Overall Knowledge Retention } \\
\hline 31 & Overall, I believe the organisation does retain the knowledge of its knowledge workers. & 22 & 29 & 25 & 24 & 0 \\
\hline
\end{tabular}

a partnership between a supervisor and a subordinate; this involves support, trust, information sharing, respect, career progress and expressing a mutual relationship. The uncertain results for statement 9 indicate that it might be possible the respondents have not been with the organisation long, do not understand the benefit of the work-life support programmes, have not been introduced to or made aware of these programmes or that they have utilised the programme, but it did not meet their needs.

The agreed result in statement 10 was supported by the literature, according to Coombs (2009) and Lacity et al. (2008). It applies to employees who seek autonomy, have the ability to make decisions, seek challenges and opportunities to apply their working skills. These authors further state that many employees want the freedom and discretion to arrange their own work, and to determine work procedures that have a positive influence on their performance and that increase their motivation.

For statement 16, the literature confirms that job stress and burnout are experienced by public sector IT professionals, due to problems that exist in filling posts, and competition between the private and public sectors for experienced IT employees (Coombs 2009; Lock 2003). In addition, continuous pressure, expectations and deadlines make employees vulnerable to work exhaustion and burnout (Lacity et al. 2009; Allen et al. 2008).

The disagreement and uncertain percentage for statement 20 is very high in comparison with the developmental statement 22 , which is about the responsibility of management. Wong et al. (2009) and Döckel et al. (2006) argue that in order to develop employee trust, management should steer clear of making dubious promises that cannot be delivered on, or commitments that cannot be achieved. The research findings establish that knowledge loss challenges derive from various factors which have an influence on the determinants and may cause barriers. The determinants are presented in Figure 3, categorised as organisational commitment, job satisfaction, job characteristics and talent management. The research findings indicate that the rules and procedures are not fairly applied to all employees, which was confirmed by Bashir and Ramay (2008). Bashir and Ramay (2008) further contend that, although the outcome may be unfavourable to all employees, fair and acceptable processes should be followed. 
The results of the investigation presented in Table 2 show a number of noticeable gaps and barriers at the organisation. It is clear from the findings that talent management and job satisfaction are barriers within the organisation. Issues of trust, procedural justice and poor salary reflect negatively and may impose barriers for the organisation. Figure 4 presents the barriers and gaps of the findings. On the issue of trust, it was found that respondents do not have trust in their managers. This is further compounded by insincere promises made by employers, as found by a number of researchers (Wong et al. 2009; Döckel et al. 2006; McKnight 2009). Emerging from the findings was communication, especially as it relates to trust. Managers should be open and honest with their communication; and the expectations of employees to management must be clearly communicated (Wong et al. 2009; Döckel et al. 2006; McKnight 2009).

The findings confirm that respondents experience lots of stress and burnout in their jobs. Lacity et al. (2008) and Allen et al. (2008) claim that continuous work pressure, deadlines and impractical expectations can make employees particularly vulnerable to work exhaustion and burnout. Coombs (2009) and Lock (2003) confirm that burnout and job stress are

\begin{tabular}{|c|c|}
\hline Determinant & Determinant \\
\hline Organisational Commitment & Job Satisfaction \\
\hline$\underline{\text { Factors }}$ & $\underline{\text { Factors }}$ \\
\hline - Procedural Justice & - Burnout \\
\hline $\begin{array}{l}\text { - } \text { Trust } \\
+ \text { Career Development }\end{array}$ & $\begin{array}{l}\text { - } \quad \text { Reward Practices } \\
\text { - Job Stress }\end{array}$ \\
\hline Determinant & Determinant \\
\hline Job Characteristics & Talent Management \\
\hline Factors & Factors \\
\hline - Poor Salary & - Mentoring Development \\
\hline + Training Opportunities & - Recruiting \\
\hline+ Autonomy & + Employee competence \\
\hline + Supervisor Support & \\
\hline + Training & \\
\hline
\end{tabular}

Note: More negative than positive factors in a determinant $=$ Barrier. More positive factors than negative factors in a determinant $=$ Gap.

FIGURE 3: The determinants. Less than $45 \%$ (minus -), more than $49 \%$ (plus + ).

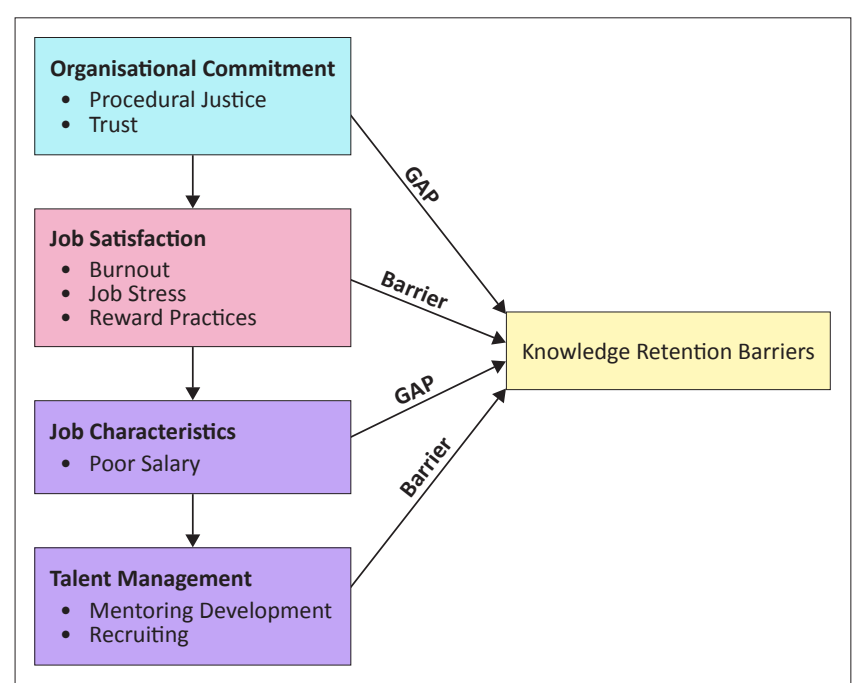

FIGURE 4: Barriers to tacit knowledge retention. experienced by public sector IT professionals due to the problems experienced in filling posts, competition between the private and public sectors for experienced IT employees, civil system rules and regulation focuses, control systems and political undercurrents. The findings confirm that the respondents do not receive adequate rewards for the job they do. As stated by Allen et al. (2008) and Döckel et al. (2009), a reward is 'an incentive given to employees in return for their job involvement, performance and recognition, which is most wanted by employees'. Lockwood and Ansari (1999) contend that an attractive base salary, with the inclusion of a bonus and stock options, is important to IT professionals. They further point out that, for the most part, government salary classification systems are restrictive when compared with those offered by the private sector.

The findings indicate that the respondents do not have a mentor to support them in their current jobs. The literature also found that mentors play a vital role in providing learning and career development opportunities for IT professionals (Van Dijk 2008). This augurs well for the continuous transfer of knowledge and contributes to easy introduction of new IT professionals into the work environment.

\section{Recommendations for further investigation}

Due to limited time, only one IT organisation was used in this study. Since the study was undertaken in the Western Cape province of South Africa, further studies of this nature could be conducted in other Information Communication Technology departments in the eight remaining provinces. These could be used to develop a roadmap of how to tackle knowledge retention challenges. It can be stated that this study has unearthed sufficient evidence to assist the organisation in its knowledge retention endeavours.

\section{Conclusion}

Knowledge retention, as identified in the literature, is important to protect the knowledge in organisations. It involves three activities: acquisition, storage and retrieval. It presents a vehicle to cut down on errors and re-inventions, and to reduce costs associated with knowledge loss. In addition, knowledge retention can be classified as an action that makes knowledge available to contribute to organisational operations and allow these operations to be sustainable through efficiency and effectiveness.

Determinants of barriers to knowledge retention were identified, such as organisational commitment, job satisfaction, job characteristics and talent management. Factors were identified and need to be measured to prevent such barriers from occurring in an organisation. Poor salaries influence IT professionals to find jobs elsewhere, which prevents core knowledge from being retained within an organisation. Furthermore, work exhaustion and burnout can occur as a result of continuous impractical work demands by the employer, which can lead to a lack of innovative thinking and services. The lack of time and the lack of mentor training 
and understanding also prevents the transfer and sharing of knowledge, which results in continuous poor skill outcomes. Finally, a lack of trust can leads to poor decision making and to poor service delivery.

This study highlights the barriers and gaps that exist in a government organisation and places renewed focus on the potential knowledge retention barriers in the context of South African government organisations.

\section{Acknowledgements Competing interest}

The authors declare that they have no financial or personal relationship(s) that may have inappropriately influenced them in writing this article.

\section{Authors' contributions}

Both authors, J.B. (University of the Western Cape) and V.N. (University of the Western Cape and University of South Africa) contributed equally to the research and the writing of this article.

\section{References}

Allen, M.W., Armstrong, D., Reid, M.F. \& Riemenschneider, C.K., 2008, 'Factors impacting the perceived organisational support of IT employees', Information \& Management 45, 556-563. http://dx.doi.org/10.1016/j.im.2008.09.003

Alwis, R.S. \& Hartmann, E., 2008, 'The use of tacit knowledge within innovative companies: Knowledge management in innovative enterprises', Journal of Knowledge Management 12(1), 133-147. http://dx.doi.org/10.1108/13673270810852449

Bashir, S. \& Ramay, M.I., 2008, 'Determinants of organisational commitment: A study of information technology professionals in Pakistan', Journal Behavioural \& Applied Management 9(2), 226-238.

Bender, S. \& Fish, A., 2000, 'The transfer of knowledge and the retention of expertise: The continuing need for global assignments', Journal of Knowledge Management 5(2), 125-137. http://dx.doi.org/10.1108/13673270010372251

Bhardwaj, M. \& Monin, J., 2007, 'Tacit to explicit: An interplay shaping organisation knowledge', Journal of Knowledge Management 10(3), 72-85. http://dx.doi. org/10.1108/13673270610670867

Bollinger, A.S. \& Smith, R.D., 2001, 'Managing organisational knowledge as a strategic asset', Journal of Knowledge Management 5(1), 8-18. http://dx.doi.org/10.1108/ 13673270110384365

Christensen, L.B., Johnson, R.B. \& Turner, L.A., 2007, Research Methods, Design, and Analysis, 11th edn., Pearson Higher Education, Boston.

Claes, R. \& Heymans, M., 2008, 'HR professionals' views on work motivation and retention of older workers: A focus group study', Career Development International 13(2), 95-111. http://dx.doi.org/10.1108/13620430810860521

Coombs, C.R., 2009, 'Improving retention strategies for IT professionals working in the public sector', Information \& Management 46, 233-240. http://dx.doi.org/10.1016/ j.im.2009.02.004

Cunningham, I., 2007, 'Talent management: Making it real', Development and Learning in Organisations 21(2), 4-6. http://dx.doi.org/10.1108/14777280710727307

Depres, C. \& Chauvel, D., 1999, 'Knowledge management(s)', Journal of Knowledge Management 3(2), 110-120. http://dx.doi.org/10.1108/13673279910275567

Döckel, A., Basson, J.S. \& Coetzee, M., 2006, 'The effect of retention factors on organisational commitment: An investigation of high technology employees', SA Journal of Human Resource Management 4(2), 20-28. http://dx.doi.org/10.4102/ sajhrm.v4i2.91

Drucker, P., 1959, Landmarks of Tomorrow, Harper and Row Publishers, New York.
Earle, H.A., 2003, 'Building a workplace of choice: Using the work environment to attract and retain top talent', Journal of Facilities Management 2(3), 244-257. $\mathrm{http}: / / \mathrm{dx}$.doi.org/10.1108/14725960410808230

Girard, J.P. \& McIntyre, S., 2010, 'Knowledge management modelling in public sector organisations: A case study', International Journal of Public Sector Management 23(1), 71-77. http://dx.doi.org/10.1108/09513551011012330

Glen, C., 2007, 'Fostering talent opportunity: Getting past first-base', Strategic Direction 23(10), 3-5. http://dx.doi.org/10.1108/02580540710824220

Jiacheng, W., Lu, L. \& Francesco, C.A., 2010, 'A cognitive model of intra-organisationa knowledge-sharing motivations in the view of cross-culture', Internationa Journal of Information Management 30, 220-230. http://dx.doi.org/10.1016/j. ijinfomgt.2009.08.007

Joseph, D., Ng, K.Y., Koh, C. \& Ang, S., 2007, Turnover of information technology professionals: A narrative review, meta-analytic structural equation modelling and model development', MIS Quarterly 31(3), 547-577.

Lacity, M.C., Iyer, V.V. \& Rudramuniyaiah, P.S., 2008, 'Turnover intentions of Indian IS professionals', Information Systems Frontiers 10(2), 225-241. http://dx.doi. org/10.1007/s10796-007-9062-3

Lehner, F. \& Haas, N., 2010, Knowledge-Management success factors - Proposal of an empirical research', Electronic Journal of Knowledge Management 8(1), 79-90.

Lock, G.E., 2003, “'Living, valuing and sharing” - A case study of retaining IT professionals in the British Columbia public service', Career Development International 8(3), 152-158. http://dx.doi.org/10.1108/13620430310471069

Lockwood, D. \& Ansari, A., 1999, 'Recruiting and retaining scarce information technology talent: A focus group study', Industrial Management \& Data System 99(6), 251-256. http://dx.doi.org/10.1108/02635579910253805

Marshall, R., 2005, 'Reinvest, recruit and rebuild to protect the future of IT', Human Resource Management International Digest 13(6), 3-5. http://dx.doi.org/10.1108/ 09670730510619240

McAdam, R., Mason, B. \& McCrory, J., 2007, 'Exploring the dichotomies within the tacit knowledge literature: Towards a process of tacit knowing in organisations' Journal of Knowledge Management 11(2), 43-58. http://dx.doi.org/10.1108/ 13673270710738906

McKnight, D.H., Phillips, B. \& Hardgrave, B.C., 2009, 'Which reduces IT turnover intention the most: Workplace characteristics or job characteristics?', Information \& Management 46, 167-174. http://dx.doi.org/10.1016/j.im.2009.01.002

Nonaka, I. \& Takeuchi, H., 1995, The Knowledge-Creating Company, Oxford University Press, New York.

Potgieter, D. \& Pretorius, L., 2009, 'Retention of technical professionals - A reminder for engineering and technology organisations', South African Institution of Civil Engineering 17(4), 37-42.

Prusak, L., 2001, 'Where did knowledge management come from?', IBM Systems Journal 40(4), 1002-1007. http://dx.doi.org/10.1147/sj.404.01002

Ramirez, Y.W. \& Nembhard, D.A., 2004, 'Measuring knowledge-worker productivity: A taxonomy', Journal of Intellectual Capital 5(4), 602-628. http://dx.doi.org/10.1108/ 14691930410567040

Reychav, I. \& Weisberg, J., 2010, 'Bridging intention and behaviour of knowledge sharing', Journal of Knowledge Management 14(2), 285-300. http://dx.doi.org/10.1108/ 13673271011032418

Riege, A., 2005, 'Three-dozen knowledge-sharing barriers managers must consider' Journal of Knowledge Management 9(3), 18-35. http://dx.doi.org/10.1108/ 13673270510602746

Rong, G. \& Grover, V., 2009, 'Keeping up-to-date with information technology: Testing a model of technological knowledge renewal effectiveness for IT professionals', Information \& Management 46, 376-387. http://dx.doi.org/10.1016/j.im.2009. 07.002

Van Dijk, H.G., 2008, 'The talent management approach to human resource management: Attracting and retaining the right people', Journal of Public Administration 43(3.1), 385-395.

Vanderstoep, S.W. \& Johnston, D.D., 2009, Research methods for everyday life, blending qualitative and quantitative approaches, Jossey-Bass, San Francisco.

Wang, P.J., 2004, 'An exploratory study of the effect of national culture on knowledge management factors, expectations and practices: A cross-cultural analysis of Taiwanese and U.S. perceptions', Unpublished doctoral dissertation, George Washington University, Washington, DC.

Wiig, K.M., 1997, 'Knowledge management: Where did it come from and where will it go?', Expert Systems with Applications 13(1), 1-14. http://dx.doi.org/10.1016/ S0957-4174(97)00018-3

Wong, A., Tong, C. \& Mula, J.M., 2009, 'Knowledge-sharing acts as a significant antecedent to organisational commitment in a Confucian culture: A quantitative
study of employees in the Hong Kong ICT industry', 20th Australasian Conference study of employees in the Hong Kong
on Information Systems, pp. 691-701. 